\title{
New hybrid active power filter for harmonic current suppression and reactive power compensation
}

\author{
Samet Biricik \\ Technological University Dublin, samet@biricikelektrik.com \\ Ozgur Cemal Ozerdem \\ European University of Lefke (Turkey) \\ Soydan Redif \\ European University of Lefke (Turkey)
}

See next page for additional authors

Follow this and additional works at: https://arrow.tudublin.ie/engscheleart2

Part of the Electrical and Computer Engineering Commons

\section{Recommended Citation \\ Biricik, Samet \& Ozerdem, Ozgur Cemal \& Redif, Soydan \& Dincer, Mustafa. (2015). New Hybrid Active Power Filter for Harmonic Current Suppression and Reactive Power Compensation. International Journal of Electronics. 103. 10.1080/00207217.2015.1116113.}

This Article is brought to you for free and open access by the School of Electrical and Electronic Engineering at ARROW@TU Dublin. It has been accepted for inclusion in Articles by an authorized administrator of ARROW@TU Dublin. For more information, please contact arrow.admin@tudublin.ie, aisling.coyne@tudublin.ie, gerard.connolly@tudublin.ie.

Funder: European Union

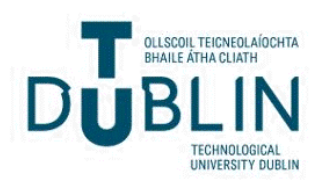




\section{Authors}

Samet Biricik, Ozgur Cemal Ozerdem, Soydan Redif, and Mustafa Sezai Dincer

This article is available at ARROW@TU Dublin: https://arrow.tudublin.ie/engscheleart2/298 
See discussions, stats, and author profiles for this publication at: https://www.researchgate.net/publication/283848633

\section{New Hybrid Active Power Filter for Harmonic Current Suppression and Reactive Power Compensation}

Article in International Journal of Electronics · November 2015

DOI: 10.1080/00207217.2015.1116113

CITATIONS

22

4 authors:

Samet Biricik

Technological University Dublin - City Campus

62 PUBLICATIONS 714 CITATIONS

SEE PROFILE

Soydan Redif

European University of Lefke

53 PUBLICATIONS 825 CITATIONS

SEE PROFILE
READS

501

Ozgur Cemal Ozerdem

European University of Lefke

27 PUBLICATIONS 364 CITATIONS

SEE PROFILE

Mustafa Sezai Dincer

Near East University

67 PUBLICATIONS 541 CITATIONS

SEE PROFILE

Some of the authors of this publication are also working on these related projects:

Load Forecasting View project

Photovoltaic Supplied Grid-Tie Inverters with Active Power Injection and PQ Compensation Capability View project 


\section{New hybrid active power filter for harmonic current suppression and reactive power compensation}

\section{Samet Biricik, Ozgur Cemal Ozerdem, Soydan Redif \& Mustafa Sezai Dincer}

To cite this article: Samet Biricik, Ozgur Cemal Ozerdem, Soydan Redif \& Mustafa Sezai Dincer (2016): New hybrid active power filter for harmonic current suppression and reactive power compensation, International Journal of Electronics, DOI: 10.1080/00207217.2015.1116113

To link to this article: http://dx.doi.org/10.1080/00207217.2015.1116113

Accepted author version posted online: 05

Nov 2015.

Published online: 29 Feb 2016.

Submit your article to this journal $๘$

Џll Article views: 38

Q View related articles $ᄃ$

View Crossmark data $־$ 


\title{
New hybrid active power filter for harmonic current suppression and reactive power compensation
}

\author{
Samet Biricik ${ }^{a, b}$, Ozgur Cemal Ozerdem ${ }^{a}$, Soydan Redifa and Mustafa Sezai Dincer ${ }^{c}$

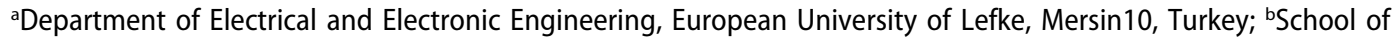 \\ Electrical and Electronic Engineering, Dublin Institute of Technology, Ireland; 'Department of Electrical and \\ Electronic Engineering, Near East University, Lefkosa, Mersin10, Turkey
}

\begin{abstract}
In the case of undistorted and balanced grid voltages, low ratio shunt active power filters (APFs) can give unity power factors and achieve current harmonic cancellation. However, this is not possible when source voltages are distorted and unbalanced. In this study, the cost-effective hybrid active power filter (HAPF) topology for satisfying the requirements of harmonic current suppression and non-active power compensation for industry is presented. An effective strategy is developed to observe the effect of the placement of power capacitors and LC filters with the shunt APF. A new method for alleviating the negative effects of a nonideal grid voltage is proposed that uses a self-tuning filter algorithm with instantaneous reactive power theory. The real-time control of the studied system was achieved with a field-programmable gate array (FPGA) architecture, which was developed using the OPAL-RT system. The performance result of the proposed HAPF system is tested and presented under nonideal supply voltage conditions.
\end{abstract}

\section{ARTICLE HISTORY}

Received 14 September 2014 Accepted 18 October 2015

\section{KEYWORDS}

Hybrid topology; active power filter real-time control; power quality; selftuning filter; current and voltage harmonics

\section{Introduction}

It is known that in industrial and domestic power distribution, the increased non-linear loads lead the transmitted power quality to degradation (Akagi, 1996). The main reason causing this is the increased power electronic loads in the systems such as motor soft starters, uninterruptible power supplies, and power converters. Such loads cause voltage or current harmonics by drawing distorted currents from the grid. Various power problems in distribution network and in consumer equipment's like blown of power capacitors, heating of transformers, neutral current increases, low power factor, if the harmonics are sufficiently large (Grady \& Santoso, 2001; Yacamini, 1995). A simple way of reducing the reactive power and current harmonics is using shunt-connected capacitors and passive filters (PFs). However, there are many disadvantages of this approach, as noted by Biricik and Ozerdem (2011). Due to their excellent compensation characteristics, much effort has been devoted to the design of active power filter (APF) (Akagi, Kanazawa, \& Nabae, 1984; Buso, Malesani, \& Mattavelli, 1998; Fujita \& Akagi, 1991; Singh, Al-Haddad, \& Chandra, 1999). APFs have several advantages over the PFs. Compensating both for the reactive power $(\mathrm{Q})$ and current harmonics dynamically is the main advantage of the APF. Using the power converters to perform the harmonic current suppression, they overcome drawbacks of the PFs; they do not cause resonances. However, simultaneously achieving well harmonic current elimination and $Q$ compensation using an APF is usually not practical. Designing the APF to reduce the non-active power with the harmonic currents increases the initial costs to very high values as the current capacity of 
power switched devices, such as metal-oxide-semiconductor field-effect transistor or insulated-gate bipolar transistor, increases with the power ratio. In recent years, to reduce the implementation cost of APFs, they are designed with shunt capacitors and/or PFs. Hybrid active power filter (HAPF) is the name given to these types of systems (Akagi, 2000; Biricik \& Ozerdem, 2010; Chen, Chenl, \& McCotmick, 2004; Singh, 2002; Venkatesh, Sarma, \& Sydulu, 2009). To improve compensation performance as well as reduce the size of an APF, a number of topologies have been proposed since the 1990s (Rahmani, Hamadi, \& Al-Haddad, 2012). The issue of where to place the PFs or shunt capacitors is one of great importance.

The converter of an APF is controlled in order to generate a filtering current that is equal to the reactive current and harmonic current. Several techniques have been introduced in the literature just to determine the harmonic and reactive components of the load current. These strategies applied to APFs have a very important role in the improvement of the performance and stability of an APF. The dynamic performance and the cost of the filter are both affected by the control strategy. Generation techniques for reference current can be classified as time domain and frequency domain. Various time-domain methods have been proposed, and the one which is called instantaneous active and reactive power theory (or $p$ - $q$ theory) was proposed by Akagi, Kanazawa, and Nabae (1984). To be able to calculate the desired compensation current, $p$ - $q$ theory basis has been used to design most APFs. However, in this case, having balanced and undistorted three-phase grid voltages is necessary for the method to work correctly (Biricik, Ozerdem, Redif, \& Kmail., 2013; Ghamri, Benchouia, \& Golea, 2012; Kale \& Özdemir, 2005; Ucar \& Ozdemir, 2008). Most control methods use the grid voltages as one of the parameters to generate the reference current. The industry frequently encounters unbalanced and distorted grid voltage conditions. The network voltages become distorted as a result of the distorted currents which cause distorted voltage drops. Different cases such as different grid impedances cause variations in the load leading unbalanced voltages. So, without properly considering these two important power quality problems, the dynamic characteristics of HAPFs will probably be adversely affected. Therefore, the gird voltage condition should be taken into account during filter design procedure (Biricik, 2013).

In this paper, a method and the results of the study for the improvement of the harmonic compensation and Q compensation capability of HAPFs where non-sinusoidal supply voltages are present are discussed. Additionally, an optimal design method to reduce the implementation costs for designing HAPFs is introduced. It is prudent to simulate the complete system model as part of the design process before implementation. Then, the real-time control of the studied system was achieved with a field-programmable gate array (FPGA) architecture, which was developed using the OPAL-RT system. The performance result of the proposed HAPF system is tested and presented under nonideal supply voltage conditions.

The proposed method improves the harmonic current elimination together with the $Q$ compensation capability of HAPFs whenever unbalanced and distorted supply voltages are present. An optimal design method for reducing implementation costs in designing HAPFs is also introduced. Advantages of our approach over previous systems are as follows:

- The converter power ratio is significantly reduced with use of the proposed HAPF

- Low current stress on the power semiconductors

- Fast reactive power compensation for the fast varying load conditions

- A reference compensating current that is adequate even for nonideal voltage and varying load conditions

\section{Proposed HAPF topology}

The work reported in this paper is concerned with three-phase systems that have either linear or non-linear load groups. In Figure 1, we show the block diagram of a basic three-phase APF 


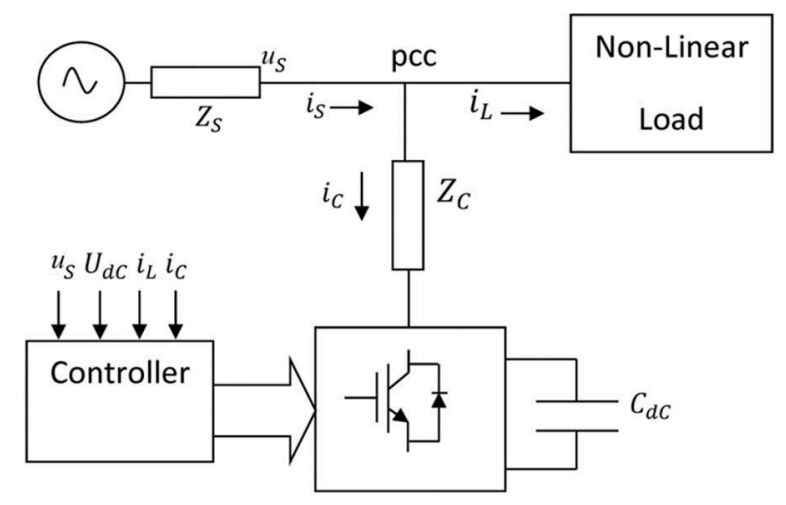

Figure 1. Pure APF block diagram.

connected to a general non-linear load. The APF compensates the current harmonics and nonactive power dynamically. The switch-mode power converter of the APF is used to remedy the chief drawback of PFs as well as suppress the current harmonics. In certain applications, the APF has been connected to the main distribution board of the system. In this type of configuration, the harmonics can wreak havoc on the internal system equipment, which cannot be prevented. One way of minimising the damage to the equipment would be to place the APF as near to the nonlinear load as possible.

A non-unity power factor arises due to the consumed non-linear, three-phase load currents. Therefore, the drawn currents from the load terminals are summation of reactive current with harmonic currents as given by:

$$
i_{L}(t)=i_{1}(t)+i_{h}(t)+i_{q}(t),
$$

where $i_{L}(t)$ is the current of the load group, $i_{1}(t)$ is the current at the fundamental frequency, $i_{h}(t)$ is the components, and $i_{q}(t)$ is the reactive (non-active) current.

$$
i_{h}(t)=\sum_{h=1}^{\infty} i_{h+2} \sin ([h+2]) \omega t+\emptyset_{h+2}
$$

APFs are controlled as a current source which is parallel to the load groups. The converter is controlled to generate a filter current, $i_{c}(t)$, which is equal to the consuming harmonic components but in opposite phase, that is,

$$
i_{c}(t)=\underbrace{\left(i_{3}(t)+i_{5}(t)+i_{7}(t)+i_{7}(t)+i_{n}(t)\right)}_{i_{h}(t)}+i_{q}(t) .
$$

Thus, an ideal source current is given at the fundamental frequency by

$$
i_{s}(t)=l_{1} \sin (\omega t) \text {. }
$$

Generation of both $i_{h}(t)$ and $i_{q}(t)$ components by the converter will increase the current capacity of the APF as seen in Equation (3), increasing the cost quite significantly. This is mainly because of the current capacity of power switched devices. The use of simple shunt-connected power capacitors or tuned passive inductive $(L)$ and capacitive $(C)$ filters with the APF is a wellknown method of compensating for the reactive power in a cost-effective manner.

It is well known that power capacitors are easy to implement and represent a cost-effective solution for the compensation of reactive power. This type of solution is widely used in the 
domestic and industrial applications to improve the system's power factor (Ozerdem \& Biricik, 2009). The inductive loads produce inductive reactive power. Conversely, capacitive reactive power is generated by capacitors, exactly complementing the inductive reactive power. In this case, the current leads the voltage by a phase angle of $90^{\circ}$. To generate required reactive power near to the load voltage, current and power factor parameters are necessary. In the following, we show how the non-active power may be determined. The apparent power consumed by the system is:

$$
S_{1}(t)=u(t) \cdot i(t)
$$

where $u(t)$ is the voltage at the grid and $i(t)$ is the terminal load current. The real power consumed by the load is:

$$
P(t)=S_{1}(t) \cdot \cos \emptyset_{1}
$$

The power factor $(p f)$ is expressed $\cos \emptyset_{1}$ (Wildi, 2006), which is the phase difference between current and voltage of the uncompensated system. The $Q$ absorbed by the load can be determined as:

$$
Q_{1}(t)=\sqrt{S_{1}^{2}(t)-P^{2}(t)}
$$

After improving $\cos \emptyset_{1}$ to $\cos \emptyset_{2}$, the new apparent power dissipated by the line is:

$$
S_{2}(t)=\frac{P}{\cos \emptyset_{2}},
$$

where $\cos \emptyset_{2}$ is the new (target) phase difference between current and voltage after $Q$ compensation. Similarly, while $\cos \emptyset$ is near to unity, the $Q$ power can be determined as:

$$
Q_{2}(t)=\sqrt{S_{1}^{2}(t)-P^{2}(t)}
$$

Subtraction of Equation (7) from (9) gives the minimum required reactive power, that is,

$$
Q(t)=Q_{1}(t)-Q_{2}(t) .
$$

The size of the compensation capacitors is given by the following:

$$
C=\frac{1}{2 \pi \cdot f \cdot X_{c}},
$$

where the capacitor reactance, $X_{c}$, is given by the voltage on the power capacitors divided by the reactive current, that is,

$$
X_{C}=\frac{u_{c}(t)}{i_{q}(t)}
$$

and the reactive current is:

$$
i_{q}=\frac{Q}{u_{s}}
$$

Switched capacitors have great importance due to the dynamic suppression of $Q$ when the load groups are varying. It is important to note that the $Q$ compensation capacitors can be obtained from suppliers by stating the kVAr value. These power capacitors are connected to the load terminal to improve the power factor. Hence, the new converter current with this topology can be defined as:

$$
i_{c}(t)=\underbrace{-\left(i_{3}(t)+i_{5}(t)+i_{7}(t)+i_{7}(t)+i_{n}(t)\right)}_{i_{h}(t)}
$$


As is indicated in Equation (14), the effect of the reactive current has been eliminated, thus reducing the APF workload. If the 3rd, 5th, and 7th harmonics remain in the system being analysed, then these harmonics can be removed using PFs. This removes the burden of cancelling for such harmonics from the power stage. A low-pass filter can be connected in parallel to the load terminal. Such a configuration can also provide $Q$ compensation in addition to current harmonic reduction. However, during load power changes, this may not show good dynamic responses in term of $Q$ compensation. A more effective solution is obtained by employing shunt switched capacitors. Moreover, the use of a well-designed low-pass filter can reduce the converter compensation currents. A single-tuned shunt filter can only eliminate a single current harmonic component. Therefore, a single-tuned filter is required for each current harmonic for successful harmonic suppression. The tuned frequency of the low-pass filters is not suggested to set high-order harmonics (Nassif, Wilsun, \& Walmir, 2009). The magnitudes of the impedances of the power capacitor and inductor are almost equal but have opposite signs at the resonance frequency. The total capacitance of the compensation capacitors is determined for the $n$th current components as follows:

$$
C_{n}=\frac{1}{2 \pi \cdot f \cdot X_{c}}
$$

where the capacitor reactance $X_{c}$ is given by the voltage on the power capacitors divided by the produced reactive power by the $n$ th-tuned filter, $Q_{n_{-} \text {filter, }}$ that is,

$$
X_{C n}=\frac{\left(u_{s}\right)^{2}}{Q_{n_{-} \text {filter }}} .
$$

Finally, the reactor inductance can be calculated as:

$$
L_{n}=\left(\frac{1}{2 \pi \sqrt{C} \cdot f_{\text {tuned }}}\right)^{2},
$$

where $f_{\text {tuned }}$ is the series resonance frequency of the filter and given by the following:

$$
f_{\text {tuned }}=\frac{1}{2 \pi(\sqrt{L C})} .
$$

Considering the connection of both the shunt capacitors and PFs to the point of common cabling (PCC), the injection current of the power converter can be given as:

$$
i_{c}(t)=-\sum_{n=9}^{\infty} i_{n}(t) .
$$

The proposed configuration is shown in Figure 2. The large varying reactive power can be compensated by using shunt capacitors, while the PFs can be used to suppress lower-order harmonics. This allows for the design of a converter with a lower power rating. The proposed HAPF topology can meet the requirements of both harmonic suppression and $Q$ compensation.

\section{Capacitor and coupling inductor design}

It is well known that the design for the DC-link stage involves the selection of the capacitor value and the capacitor voltage rating. In this section, we first introduce a new method for determining the voltage on the DC-link converter. Additionally, a method for selecting the DC-link capacitor value is then detailed. 


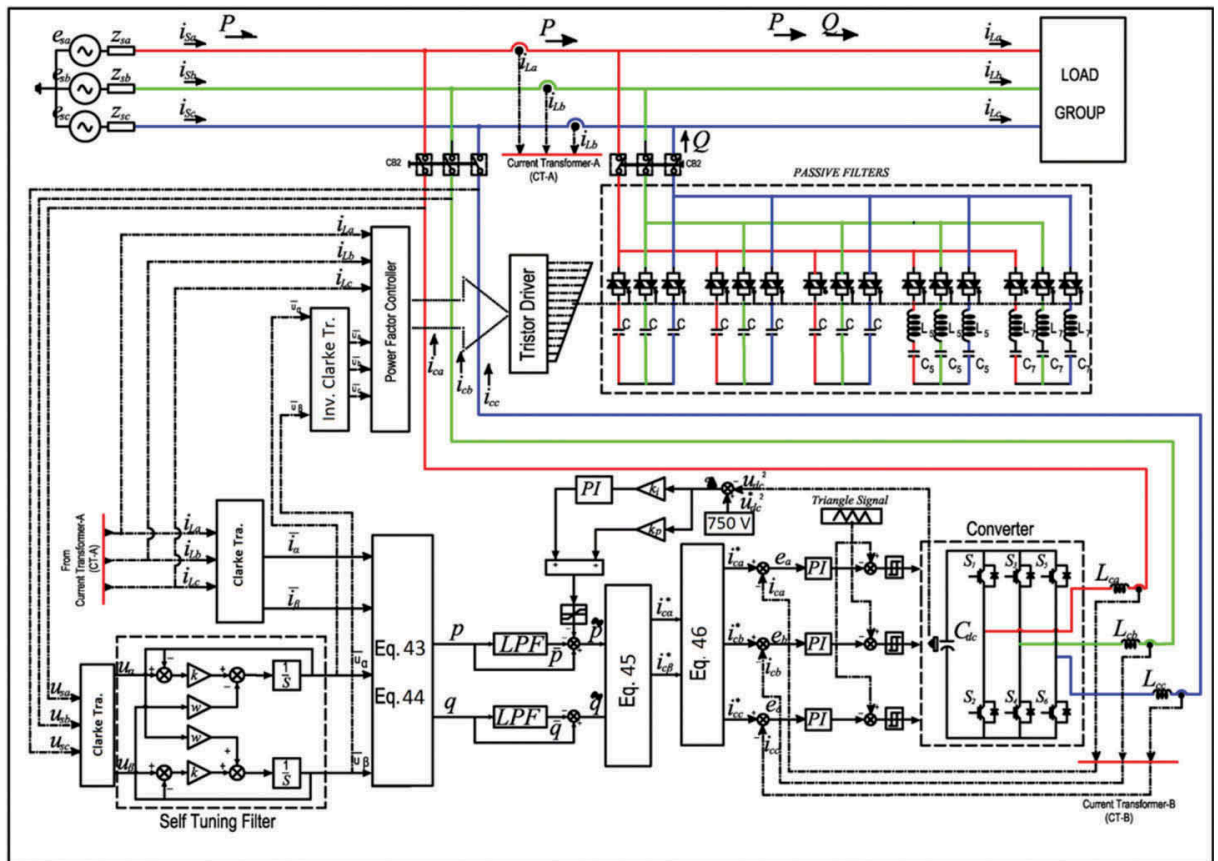

Figure 2. Overall block diagram of the proposed HAPF.

\subsection{Determination of the DC-link voltage}

The selection of the voltage on the DC-link rating, $U_{d c}$ rating, should be determined according to the peak value of the grid voltage, $u_{s(\text { peak })}$. In order to transfer the active current from the capacitor to the load, the voltage on the DC link should be set higher than the peak value of the grid. However, it should be limited because high voltage ratios can increase the switching losses of the converter. If the DC-link capacitance is not adequate, the filter inductor current will not vary smoothly. On the other hand, the system dynamic response will suffer if capacitance is greater than that required. Therefore, we aim to satisfy the following criteria:

$$
\begin{gathered}
u_{s}(t)=U_{s(\text { peak })} \cdot \sin (\omega t), \\
U_{d c}(t)>U_{s(\text { peak })} .
\end{gathered}
$$

According to Equation (21), lowest voltage ratio of the DC link can be calculated as:

$$
U_{d c(\min )}=\underbrace{\sqrt{2} \cdot u_{s}}_{U_{s(\text { peak })}} .
$$

The relation between the DC side terminal voltage, $u_{d c}(t)$, and the DC side input current $i_{d c}(t)$, is

$$
i_{d c}(t)=C_{d c} \frac{d U_{d c}}{d t}
$$

where $C_{d c}$ is the capacitor value in Farad. The Laplace transform of Equation (23) gives the following transfer function: 


$$
G(s)=\frac{u_{(s)}}{i_{(s)}}=\frac{1}{s C}
$$

In order to analysis the best DC-link voltage, several simulations were performed and graphical representation of the data is plotted in Figure 3. It is important to mention that the data are collected for a $240 \mathrm{~V}$ line to neutral, $U_{L-N(r m s)}$, ideal grid voltage. The other system parameters are presented in Table 1.

As shown in Figure 3, the voltage increases at the DC-link voltage terminals may affect the behaviour of the system negatively. This is mainly because high capacitor voltage value can increase the switching losses of the converter, as mentioned earlier. Therefore, as a precaution, the maximum value of the capacitance voltage should be determined a priori. Based on these results, Equation (25) can be used to calculate maximum DC-link voltage of a three-phase converter:

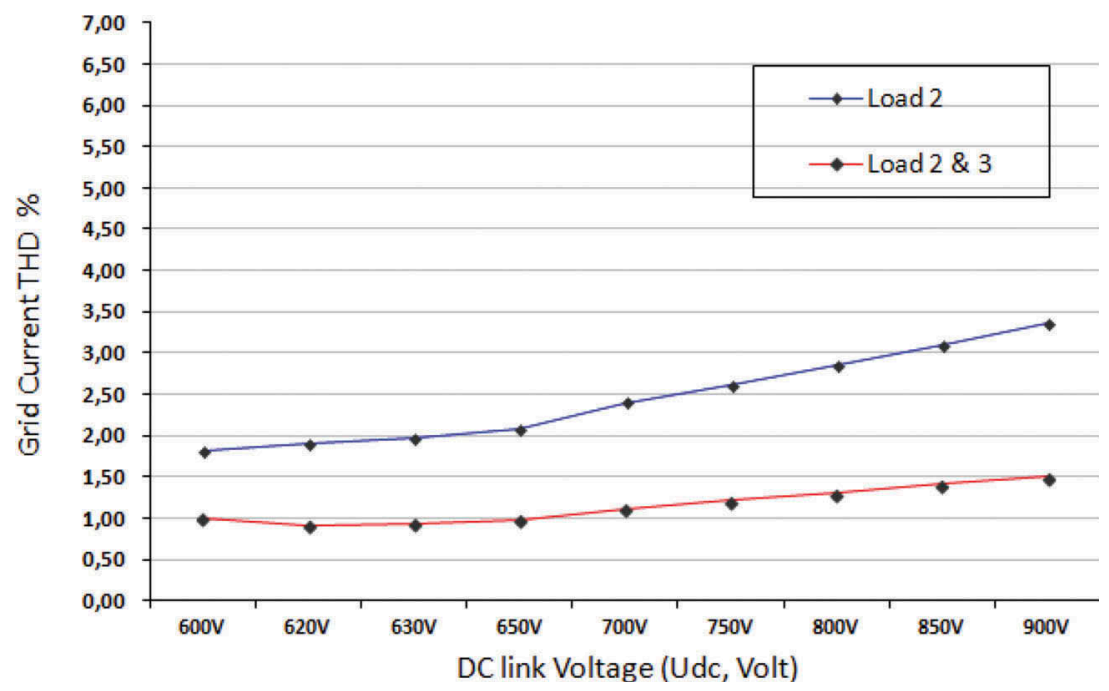

Figure 3. The current harmonic compensation of the APF under different DC-link voltage values.

Table 1. Parameters of the analysed system.

\begin{tabular}{lll}
\hline Symbol & \multicolumn{1}{c}{ Quantity } & Value \\
\hline$u_{S}$ & Ideal Grid L-N RMS Voltage & $240 \mathrm{~V}$ \\
$f$ & Network frequency & $50 \mathrm{~Hz}$ \\
$R_{s}$ & Network resistance & $3 \mathrm{~m} \Omega$ \\
$L_{s}$ & Network impedance & $2.6 \mu \mathrm{H}$ \\
Rac \& Lac & AC resistance \& inductance & $10 \mathrm{~m} \Omega, 0.3 \mathrm{mH}$ \\
Load 1 & Linear Load Res. \& Ind. & $4 \Omega, 10 \mathrm{mH}$ \\
Load 2 & Non-linear Load Res. \& Cap. & $8 \Omega, 1.3 \mathrm{mf}$ \\
Load 3 & Non-linear Load Res. \& Cap. & $12 \Omega, 1.3 \mathrm{mf}$ \\
$L_{f}$ & Filter inductor & $1 \mathrm{mH}$ \\
$C_{d c}$ & Converter dc Capacitor & $9000 \mu \mathrm{ff}$ \\
$U_{d c}$ & DC-link voltage & $750 \mathrm{~V}$ \\
$K p$ & Proportional gain & 0.09329 \\
$K i$ & Integral gain & 1.24357 \\
$L_{5}, C_{5}$ & 5th order filter Ind. \& Cap. & $3.1 \mathrm{mH}$ and $130 \mu \mathrm{ff}$ \\
$L_{7} C_{7}$ & 7th order filter Ind. \& Cap. & $3.4 \mathrm{mH}$ and $60 \mu \mathrm{f}$ \\
$f_{s}$ & Switching frequency & $14 \mathrm{kHz}$ \\
$K$ & STF & 100 \\
\hline
\end{tabular}




$$
U_{d c(\max )}=\underbrace{1.5 \sqrt{2} u_{s}}_{U_{s(\text { peak })}} .
$$

Therefore, the required average voltage at the DC bus for three-phase APFs can be determined by

$$
U_{d c}=\frac{U_{d c(\max )}+U_{d c(\min )}}{2}
$$

where $u_{d c(\min )}$ is the lowest and $u_{d c(\max )}$ is the highest DC-link voltage. Finally, Equation (26) can be simplified as:

$$
U_{d c}=1.7677 \times\left(u_{s}\right)
$$

\subsection{DC-link capacitance value design}

The aim of the DC capacitor at the converter is to supply or absorb active power to the PCC during transient behaviour (Singh, Singh, \& Mitra, 2007). Benchaita, Saadate, and Salem (1999) used the following expression in order to determine the DC-link capacitor value:

$$
C_{d c}=\frac{\tilde{p}}{2 \pi f u_{d c} \Delta U_{d c}}
$$

where $\tilde{p}$ is the harmonic power which will be injected by the converter and $\Delta u_{d c}$ is the DC-link voltage ripple. In the same year, Chatterjee, Fernandes, and Dubey (1999) proposed a method for obtaining the value of the DC-link capacitor. This method is based on the maximum active power rating of the load. Therefore, during the peak power of the load, the maximum energy that the DClink capacitor has to supply for the worst case transient is given by:

$$
E_{\max }=P_{\max } 20 \times 10^{-3} \mathrm{~J},
$$

where $P_{\max }$ is the total consumed active power by the load. After calculation of the minimum voltage for the DC link by Equation (29),

$$
E_{\max }=\frac{1}{2} C_{d c} U_{d c}^{2}-\frac{1}{2} C_{d c} U_{d c(\min )}^{2}
$$

the size of the DC-link capacitor is obtained via

$$
C_{d c}=\frac{2 P_{\max } 20 \times 10^{-3} \mathrm{~J}}{U_{d c}^{2}\left[1-\left(\frac{U_{d c(\min )}}{U_{d c}}\right)^{2}\right]} .
$$

Equation (28) is not of much use when the characteristics of the load groups are not known well. However, it gives the optimum capacitor value if the maximum harmonic power is known. The second method, as given in Equation (31), is based on total active power of the load groups, $P_{\max }$. This method may be useful when the harmonic analysis does not apply, or in cases where the load groups are highly variable. In the specific systems, the $C_{d c}$ can be chosen of a higher value to obtain a lower steady ripple state and better transient response (Khadem, Basu, \& Conlon, 2013). However, the result in Equation (28) is more economical than Equation (31). Therefore, applicability of either method depends on the situation. 


\subsection{Design criteria of the filter inductances}

The three-phase, three-leg APF consists of three inductors $\left(L_{c a}, L_{c b}, L_{c c}\right)$ and converter that are directly connected to PCC. It is important to mention that these inductors are not for filtering, but rather AC-coupling inductor. Another important point is that the inductor current capacity should be higher than the peak value of the APF currents to cater for current ripples on top of the fundamental peak value of current. Furthermore, there are two important issues that are of concern when selecting the filter inductor. These are the switching losses and system response. Here, we outline a method for determining the inductor value proposed by Moran, Dixon, and Wallace (1995). To begin with, the slope of the triangle waveform, $m$, is determined by

$$
m=4 h f,
$$

where $m$ is the maximum ripple current, $h$ is the peak value of the triangle waveform, and $f$ is the switching frequency. The maximum coupling inductances, $L_{c a(\max )}$, on the first phase can be determined by

$$
L_{c a(\max )} \frac{d i_{c a}}{d t}=u_{s a(\text { peak })}+u_{d c(\max )},
$$

where $u_{\text {sa(peak) }}$ is the peak voltage level of the phase-a, and $u_{d c(\max )}$ is the maximum voltage on the DC link. And the maximum slope of the filter current at each phase can be expressed as

$$
m_{(\max )}=\frac{d i_{c a}}{d t}=\frac{u_{s a(\text { peak })}+u_{d c(\max )}}{L_{c a(\max )}} .
$$

Finally, the minimum inductance can be chosen such that

$$
L_{c a(\min )}=\frac{u_{s a(\text { peak })}+u_{d c(\max )}}{m} .
$$

The APF inductance must be set to the correct value in order that the current reaches the reference current at the required time.

\section{Proposed control method}

The control method plays an important role in the performance and stability of power electronic devices, particularly when dealing with nonideal supply voltages. In this section, we propose a control method for the HAPF, introduced in Section 2, which can also suppress for effects of distorted and unbalanced grid voltages.

First proposed by Akagi et al., in 1984, $p-q$ theory is the most prevalent control method in the literature. The main idea behind this control method is that the generated harmonic components can be supressed with other non-linear controlled loads. The three-phase supply voltages $\left(u_{s a}, u_{s b}, u_{s c}\right)$ and load currents $\left(i_{L a}, i_{L b}, i_{L c}\right)$ are converted into an alpha and beta coordinate system by using the Clarke transform, which yields instantaneous $P$ and $Q$ power components. After obtaining the alpha and beta current waveforms, the active and non-active instantaneous powers ' $p$ ' and ' $q$ ' can be found as:

$$
p=u_{s a} i_{L a}+u_{s \beta} i_{L \beta}+u_{s 0} i_{L 0}
$$

and

$$
q=u_{s a} i_{L \beta}-u_{s \beta} i_{L a}
$$

These relations can be expressed in a matrix form as: 


$$
\left[\begin{array}{l}
p \\
q \\
0
\end{array}\right]=\left[\begin{array}{ccc}
u_{s a} & u_{s \beta} & 0 \\
-u_{s \beta} & u_{s a} & 0 \\
0 & 0 & u_{0}
\end{array}\right]\left[\begin{array}{c}
i_{L a} \\
i_{L \beta} \\
i_{L 0}
\end{array}\right]
$$

The instantaneous $P$ and $Q$ power components each consists of a continuous term, at the fundamental frequency, and a harmonic term. The latter constitutes the alternating harmonic component of the current and voltage. These components can be separated by way of low-pass filtering. The current reference signal is obtained by:

$$
\left[\begin{array}{l}
i_{c a}^{*} \\
i_{c \beta}^{*}
\end{array}\right]=\frac{1}{u_{s a}^{2}+u_{s \beta}^{2}}\left[\begin{array}{cc}
u_{s a} & u_{s \beta} \\
u_{s \beta} & u_{s a}
\end{array}\right]\left[\begin{array}{c}
\tilde{p}-p_{d c} \\
\tilde{q}
\end{array}\right],
$$

where the term $p_{d c}$ is the active power losses of the converter. This $u_{d c}$ value can be obtained from a proportional-integral (PI) regulation loop by measuring of DC-link voltage.

A drawback of $p-q$ theory is that it is susceptible to distorted and unbalanced grid supplies. This is evident from Equation (39), where such nonideal three-phase supplies would cause corruption of the final parameters and thus degrade the performance of the system. The degrading effect of nonideal grid supplies on the performance of the $p$ - $q$ theory was reported by Biricik et al. (2013), where it is shown how an adaptive filter, called the self-tuning filter (STF), can be adapted to $p-q$ theory in order to improve its resilience to a corrupted supply voltage (Abdusalam, Poure, \& Saadate, 2007; 2008, 2009; Biricik, Ozerdem, Redif, \& Kmail, 2012; 2014).

Here, we use the STF algorithm to improve the performance of the proposed HAPF in reducing harmonics; particularly, undistorted and balanced voltages are extracted from the distorted and asymmetrical source by filtering the distorted $\alpha-\beta$ components. This in effect suppresses the corruptive effects of the nonideal grid supply. The block diagram of the $p$ - $q$-based APF using the STF is given in Figure 2. The transfer function of the STF is given by the integration of the synchronised reference signal, that is,

$$
H(s)=\frac{V_{x y}(s)}{U_{x y}(s)}=\frac{s+j \omega}{s^{2}+\omega^{2}},
$$

where

$$
V_{x y}(t)=e^{j \omega t} \int e^{-j \omega t} U_{x y}(t) d t
$$

It can be shown that the magnitude/phase response of the STF is similar to that of a bandpass filter. Since the STF preserves phase, the input $U_{x y}(s)$ and output $V_{x y}(s)$ voltages have the same phase. A unit magnitude response can be obtained by inclusion of a constant $k$ into Equation (40), thus

$$
H(s)=\frac{V_{x y}(s)}{U_{x y}(s)}=k \frac{(s+k)+j \omega}{(s+k)^{2}+\omega^{2}} .
$$

This transfer function is depicted by flow diagram in Figure 4.

It is clear from Figure 4 that the stationary reference components are given by:

$$
\begin{aligned}
& \bar{u}_{a}(s)=\frac{k}{s}\left[u_{a}(s)-\bar{u}_{a}(s)\right]-\frac{\omega}{s} \bar{u}_{\beta}(s), \\
& \bar{u}_{\beta}(s)=\frac{k}{s}\left[u_{\beta}(s)-\bar{u}_{\beta}(s)\right]+\frac{\omega}{s} \bar{u}_{a}(s) .
\end{aligned}
$$




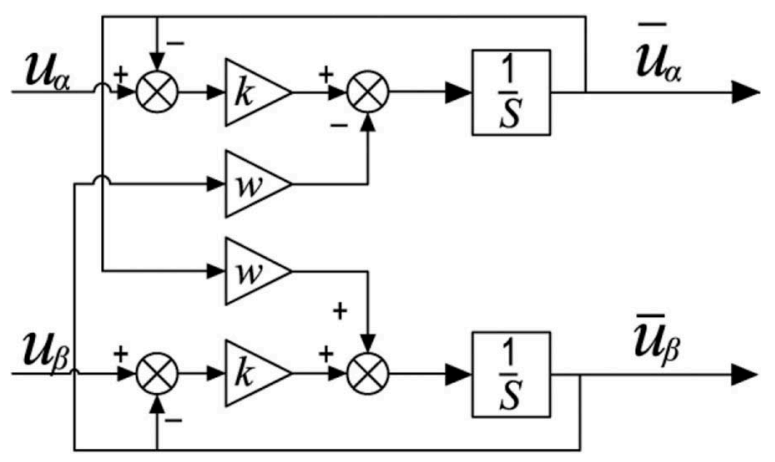

Figure 4. Principle scheme of the STF.

Equations (43) and (44) constitute the undistorted and balanced reference components, obtained from the distorted and unbalanced signals, which can now be used to provide the converter current reference signals in Equation (45), that is,

$$
\left[\begin{array}{l}
i_{c a}^{*} \\
i_{c \beta}^{*}
\end{array}\right]=\frac{1}{\bar{u}_{\alpha}^{2}+\bar{u}_{\beta}^{2}}\left[\begin{array}{cc}
\bar{u}_{a} & \bar{u}_{\beta} \\
\bar{u}_{\beta} & \bar{u}_{a}
\end{array}\right]\left[\begin{array}{c}
\tilde{p}-p_{d c} \\
\tilde{q}
\end{array}\right] .
$$

The three-phase reference currents of the HAPF are found by applying the inverse Clark transform to the stationary reference currents, that is,

$$
\left[\begin{array}{l}
i_{c a}^{*} \\
i_{c b}^{*} \\
i_{c c}^{*}
\end{array}\right]=\sqrt{\frac{2}{3}}\left[\begin{array}{cc}
1 & 0 \\
-\frac{1}{2} & \frac{\sqrt{3}}{2} \\
-\frac{1}{2} & -\frac{\sqrt{3}}{2}
\end{array}\right]\left[\begin{array}{l}
i_{c a}^{*} \\
i_{c \beta}^{*}
\end{array}\right] .
$$

The STF algorithm can be used as a simple but effective method of suppressing the negative effects of grid voltages, which allows for improved harmonic compensation by the HAPF. This algorithm is used to filter distorted $a-\beta$ quantities in order to extract the ideal and balanced voltages from the distorted and asymmetrical source. The block diagram of the $p$ - $q$-based APF using the STF is given in Figure 4.

\section{Real-time laboratory results}

In this section, we provide the results of an evaluation of the proposed HAPF method by way of real-time study on the RT-LAB platform. Employing software-in-the-loop, the proposed control system was verified via the OPAL-RT OP5600 platform, which constitutes the real-time laboratory set-up (see Figure 5). This platform controls the interactions between the console PC, from which primary simulation is managed, the CPUs, and the FPGA architecture.

Hardware implementation of the proposed power system was achieved with an FPGA architecture, which was developed using the Xilinx system generator tool. As will be seen in this section, the performance of the proposed HAPF system is tested under nonideal supply conditions. System parameters used in these experiments are given in Table 1.

The loads Load $1(L 1)$, Load 2 (L2), Load $3(L 3)$, and combinations were connected to the grid under ideal grid voltage condition. Then, the system responses are analysed. The three-phase, sixpulse un-controlled full-bridge rectifiers are used to create current harmonic components with Load 1 and Load 2. The Load 3 is a linear load and consuming active and reactive power from the grid.

The power quality analysis results are given in Table 2 . Analysis of the system has revealed that the dominant harmonics are the 5th and 7th harmonics - the third harmonic is considerably weaker in 


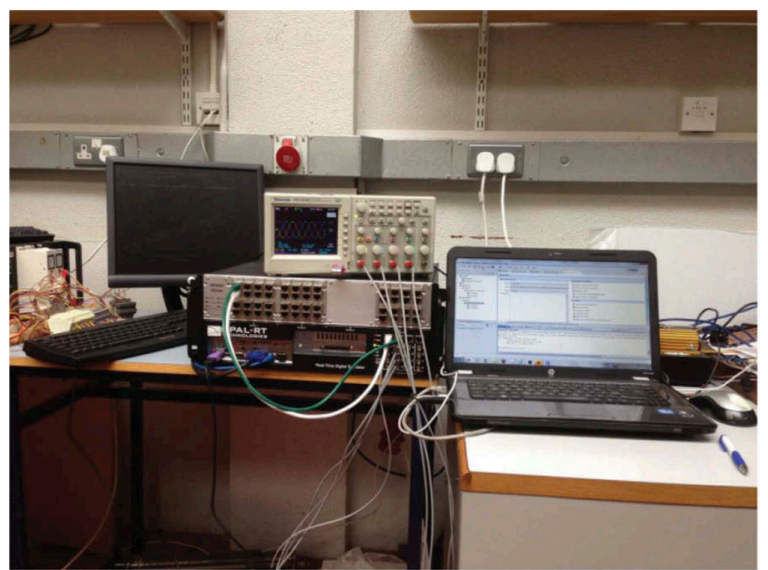

Figure 5. Experimental set-up with the OPAL-RT.

Table 2. Load analyses under ideal grid voltage condition.

\begin{tabular}{|c|c|c|c|c|c|c|c|c|c|c|}
\hline \multirow{2}{*}{ Phase } & & \multicolumn{3}{|c|}{$\begin{array}{l}\text { Load } 1 \text { (L1) } \\
\text { Phase }\end{array}$} & \multicolumn{3}{|c|}{$\begin{array}{c}\text { Load } 2 \text { (L2) } \\
\text { Phase }\end{array}$} & \multicolumn{3}{|c|}{$\begin{array}{c}\text { Load } 3(L 3) \\
\text { Phase }\end{array}$} \\
\hline & & a & $\mathrm{b}$ & C & $a$ & $\mathrm{~b}$ & c & a & $\mathrm{b}$ & C \\
\hline \multirow{2}{*}{\multicolumn{2}{|c|}{$\begin{array}{l}P(\mathrm{~kW}) \\
Q(\mathrm{kVAr})\end{array}$}} & \multicolumn{3}{|c|}{30.7} & \multicolumn{3}{|c|}{40.7} & \multicolumn{3}{|c|}{26} \\
\hline & & & 8.6 & & & 9.9 & & & 21 & \\
\hline \multicolumn{2}{|c|}{$i(\mathrm{~A})$} & 42.83 & 43.24 & 43.01 & 57.09 & 58.84 & 58.45 & 46.42 & 46.1 & 46.38 \\
\hline \multicolumn{2}{|c|}{$u(\mathrm{~V})$} & 240 & 0.81 & 240 & 240 & 240 & 240 & 240 & 240 & 240 \\
\hline \multicolumn{2}{|c|}{$\mathrm{THD}_{\mathrm{v}}(\%)$} & 0 & 0 & 0 & 0 & 0 & 0 & 0 & 0 & 0 \\
\hline \multicolumn{2}{|c|}{$\mathrm{THD}_{\mathrm{i}}(\%)$} & 26.99 & 26.99 & 26.44 & 64.43 & 55.40 & 47.71 & 0 & 0 & 0 \\
\hline \multirow{10}{*}{$\left.i_{n}\right\}$} & $i_{3}(\%)$ & 0.83 & 0.83 & 0.08 & 9.19 & 6.19 & 11.38 & 0 & 0 & 0 \\
\hline & $i_{5}(\%)$ & 20.39 & 20.39 & 19.82 & 58.26 & 48.95 & 40.22 & 0 & 0 & 0 \\
\hline & $i_{7}(\%)$ & 12.74 & 12.74 & 13.01 & 23.40 & 22.98 & 21.79 & 0 & 0 & 0 \\
\hline & $i_{9}(\%)$ & 0.81 & 0.81 & 0.04 & 3.70 & 4.20 & 0.64 & 0 & 0 & 0 \\
\hline & $i_{11}(\%)$ & 8.31 & 8.31 & 7.78 & 7.93 & 6.86 & 4.74 & 0 & 0 & 0 \\
\hline & $i_{13}(\%)$ & 5.86 & 5.86 & 6.10 & 4.09 & 3.87 & 4.31 & 0 & 0 & 0 \\
\hline & $i_{15}(\%)$ & 0.73 & 0.73 & 0.03 & 1.68 & 1.92 & 0.32 & 0 & 0 & 0 \\
\hline & $i_{17}(\%)$ & 4.51 & 4.51 & 4.03 & 3.74 & 3.25 & 1.97 & 0 & 0 & 0 \\
\hline & $\mathrm{I}_{19}(\%)$ & 3.08 & 3.08 & 3.27 & 1.61 & 1.50 & 1.89 & 0 & 0 & 0 \\
\hline & $\mathrm{I}_{21}(\%)$ & 0.62 & 0.62 & 0.02 & 1.02 & 1.16 & 0.21 & 0 & 0 & 0 \\
\hline
\end{tabular}

comparison. For full load condition $(L 1+L 2+L 3), \mathrm{P}$ is around $93 \mathrm{~kW}, \mathrm{Q}$ is around $39.50 \mathrm{kVAr}$, and $\mathrm{S}$ was measured as $101 \mathrm{kVA}$. In this study, the distorted and unbalanced supply voltage was programmed as given in Equation (47). Figure 6 shows the grid voltage, $u_{s}$, waveform. Notice that these waveforms are not pure sinusoids. Under this condition, the load current waveform is seen in Figure 7.

$$
\left.\begin{array}{l}
u_{s a}=340 \sin (\omega t)+30 \sin (5 \omega t)+20 \sin (7 \omega t)+7 \sin (11 \omega t) \\
u_{s b}=320 \sin (\omega t-2 \pi / 3)+35 \sin (5 \omega t-2 \pi / 3)+9 \sin (7 \omega t-2 \pi / 3)+10 \sin (11 \omega t-2 \pi / 3) \\
u_{s b}=350 \sin (\omega t+2 \pi / 3)+19 \sin (5 \omega t+2 \pi / 3)+15 \sin (7 \omega t+2 \pi / 3)+13 \sin (11 \omega t+2 \pi / 3)
\end{array}\right\} .
$$

Figure 8(a) shows distorted voltage with current waveforms at phase-a at the load bus. As can be given in Figure $8($ b), compensation of the large reactive power and dominant harmonics currents (5th and 7th) are achieved using shunt capacitor banks and PFs. As a result, the THDi is reduced from $25 \%$ to $12 \%$ as seen in Figure $8(\mathrm{~b})$. As a consequence, the load on the converter was 


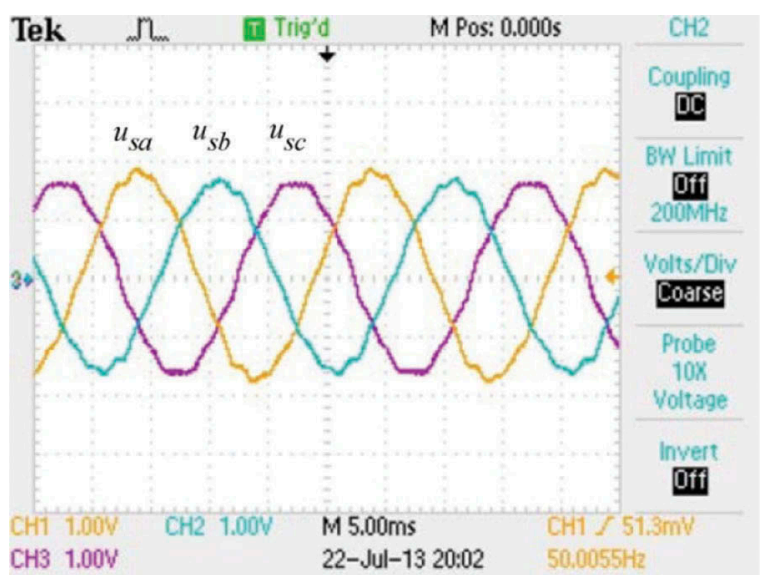

Figure 6. Three-phase nonideal grid voltages (scale: $190 \mathrm{~V} /$ div.).

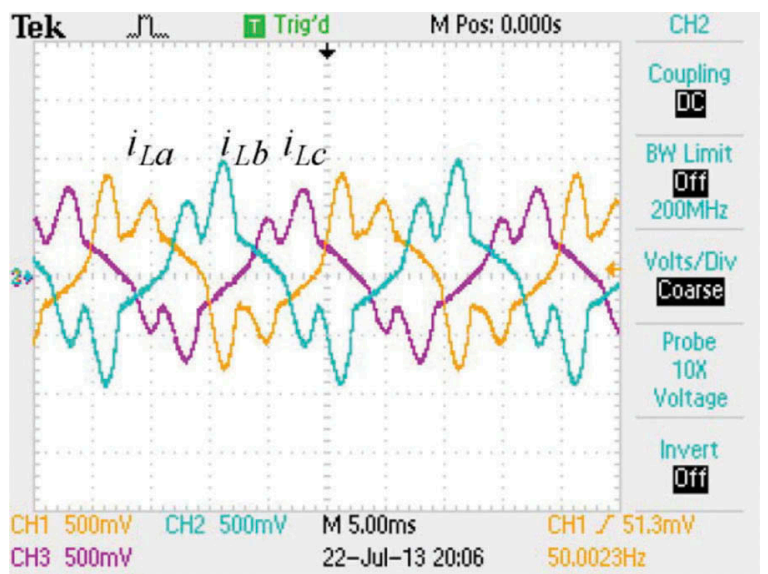

Figure 7. Three-phase non-linear load currents (scale: $90 \mathrm{~A} / \mathrm{div}$.$) .$

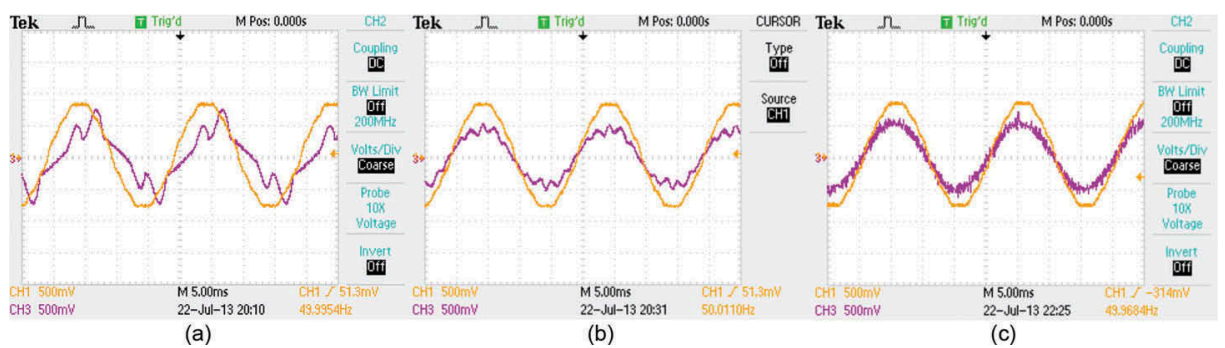

Figure 8. Waveforms at phase-a. (a) Grid voltage with load current (scale: $90 \mathrm{~A} / \mathrm{div}$.). (b) Grid voltage with load current after passive filtering (scale: $90 \mathrm{~A} /$ div.). (c) Grid voltage with grid current after HAPF (scale: $90 \mathrm{~A} / \mathrm{div}$.).

lessened and, therefore, the physical size of the converter was reduced. Figure 8(c) shows the grid current with voltage at phase-a after operation of the HAPF converter. Operation of the proposed HAPF can be seen in Figures 9, 10, and 11 for each phase. 


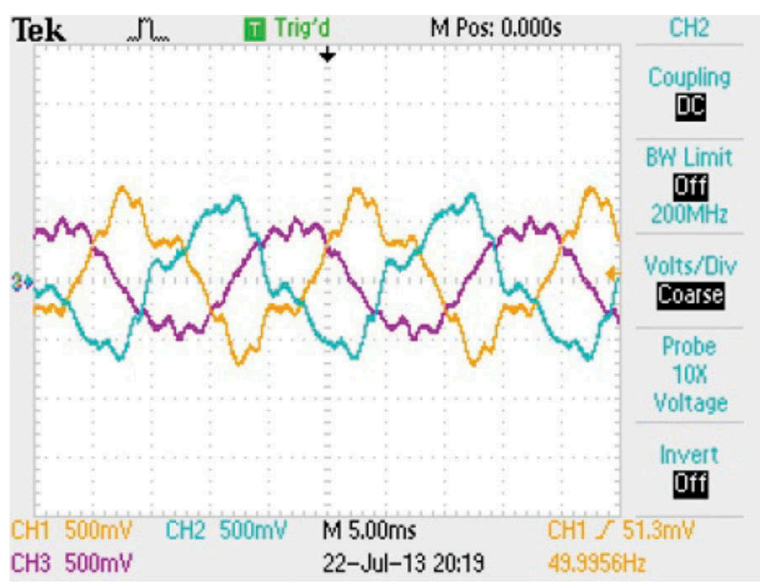

Figure 9. Grid current waveforms after compensating 5th and 7th harmonics by using tuned PFs and reactive power compensation capacitors (scale: $90 \mathrm{~A} / \mathrm{div}$.).

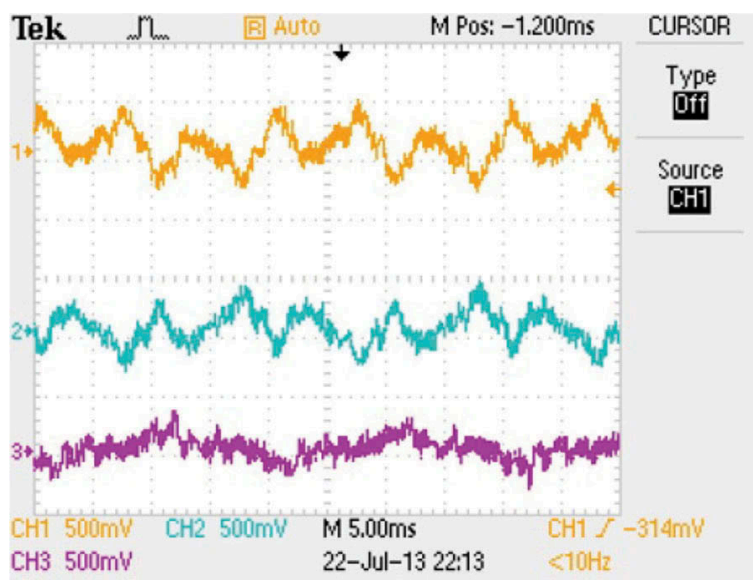

Figure 10. Injected converter current (scale: $90 \mathrm{~A} /$ div.).

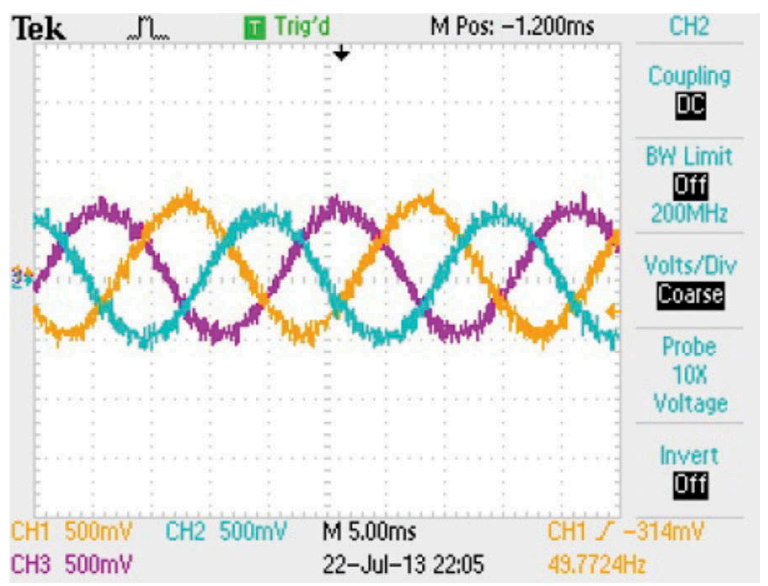

Figure 11. Grid current after filtering by proposed topology and control method under nonideal grid conditions (scale: $90 \mathrm{~A} / \mathrm{div}$.). 


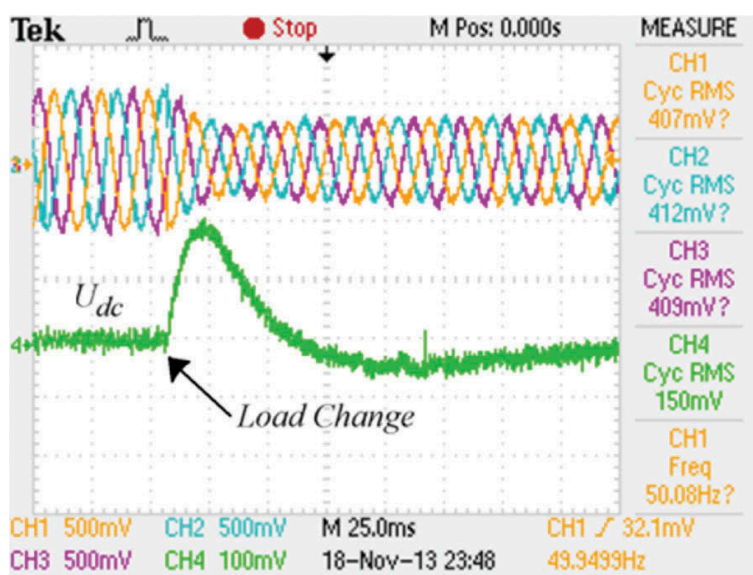

Figure 12. DC-link voltage and current waveforms at phase-a during load decreasing (scale: $90 \mathrm{~A} /$ div., $10 \mathrm{~V} /$ div).

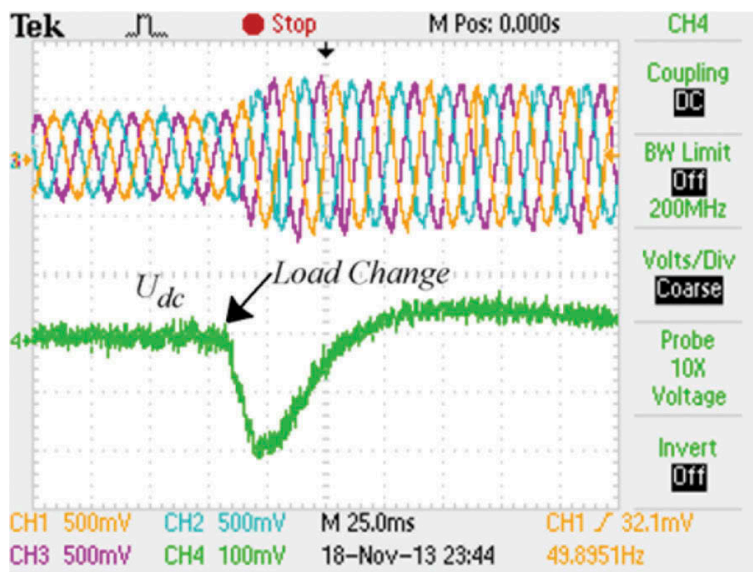

Figure 13. DC-link voltage and current waveforms at phase-a during load increasing (scale: $90 \mathrm{~A} / \mathrm{div} ., 10 \mathrm{~V} / \mathrm{div}$ ).

In our study, the reduction on the converter power ratio was about 30\%. By the same token, the size of the converter is further reduced due to the use of the PFs for compensation of the dominant harmonics. An additional advantage is gained here due to the fact that the problem of harmonic current cancellation is broken down into smaller sub-problems, each of which requiring less power in achieving the goal of harmonic compensation. Additionally, the probability of fault occurrence is minimised.

The load change operation comprises the addition of all other loads to create an average load change of 50\%. As shown in Figures 12 and 13, the current magnitude at the load terminal changed and the proposed control method compensated the grid current dynamically under both load change conditions. Moreover, the DC-link voltage (green plot) is maintained with the proposed control method as required under the dynamic load change.

\section{Discussion}

The PFs and shunt capacitors are connected to the load bus and this causes effective reduction in the 5th and 7th dominant harmonics. Moreover, the required reactive power of the loads is compensated by the shunt compensation capacitors. As a result, non-active power consumption 


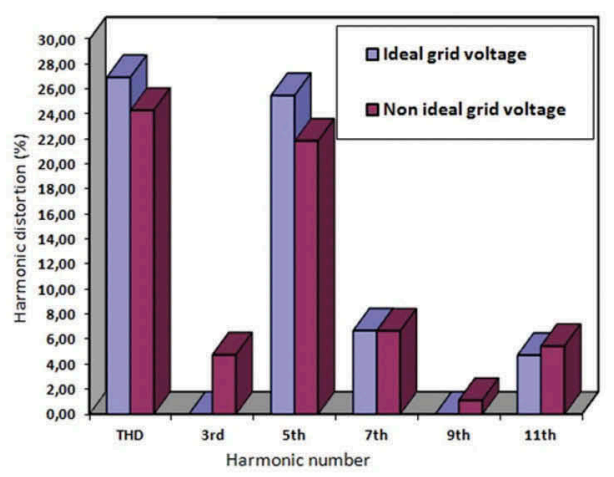

a-)

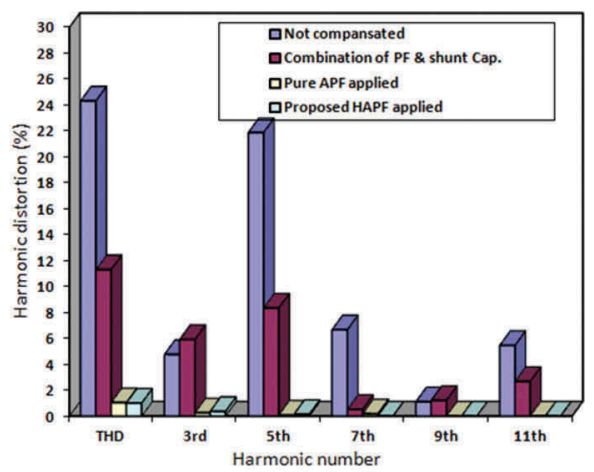

b-)

Figure 14. (a) Comparison of the harmonic distortions of the load groups under ideal and nonideal grid voltage conditions at phase-a (b)Performance comparison of the filters under nonideal grid voltage at phase-a.

from the grid was nearly eliminated. The rest of the harmonics are suppressed with the HAPF converter current. This allows for the design of a lower power rating converter. To verify the performance of the proposed control theory, the proposed HAPF is investigated under distorted and unbalanced grid voltage condition. Figure 14(a) and (b) shows the load current comparison under distorted and non-distorted grid voltage condition at phase a.

Moreover, Figure 14(a) and (b) shows that the harmonic suppression performance results are quite similar during the use of pure APF and HAPF with the proposed control method. As seen in Figure 14(b), the presence of distortion on the load voltage has a negative effect on the performance of the system. The THD of the grid current is over $3 \%$, compared to only $1 \%$ obtained with proposed HAPF with improved control method. It is clear that the working characteristic and performance of the APF systems under highly distorted grid voltage condition is negatively affected. However, the studied HAPF with improved control method has reduced the grid current harmonics to around $1 \%$. Besides this, the consumed reactive power is fully compensated.

\section{Conclusion}

In this paper, a topology for hybrid APF is presented for harmonic current elimination and compensation of non-active power under variable load condition. Moreover, an effective control strategy is developed for improving the elimination of current harmonic components efficiency of the HAPF under unbalanced and distorted grid voltages. As a result, the proposed topology presented in this study allows for the design and use of a smaller size converter, which means that the power rating and cost of the HAPF is considerably reduced. The performance of the proposed system is studied step by step. The real-time experimental results show that the studied HAPF topology with control method is providing good solution for both current harmonic mitigation power factor improvements with reducing the kVA rating of converter.

\section{Acknowledgements}

The authors acknowledge the advices and criticisms of Dr. Malabika Basu from Dublin Institute of Technology, Ireland. The authors also deeply appreciate Prof. Dr. Senol Bektas (Near East University), Prof. Dr. Osman Kükrer (Eastern Mediterranean University), Assist. Prof. Dr. Murat Fahrioğlu (Middle East Technical University), and Dr. Shafiuzzaman K. Khadem (International Energy Research Centre, Ireland) for their valuable comments and interest in this project. 


\section{Disclosure statement}

No potential conflict of interest was reported by the author.

\section{Funding}

This work is supported by the European Union under contract no: 2012/307-675.

\section{References}

Abdusalam, M., Poure, P., Karimia, S., \& Saadate, S. (2009). New digital reference current generation for shunt active power filter under distorted voltage conditions. Electric Power Systems Research, 79, 759-776. doi:10.1016/j. epsr.2008.10.009

Abdusalam, M., Poure, P., \& Saadate, S. (2007). A new control scheme of hybrid active filter using self-tuning-filter. In International conference on power engineering, energy and electrical drives, POWERENG 2007 (pp.35-40). Portugal: IEEE. doi:10.1109/POWERENG.2007.4380095

Abdusalam, M., Poure, P., \& Saadate, S. (2008). Hardware implementation of a three-phase active filter system with harmonic isolation based on self-tuning-filter. In Power electronics specialists conference, PESC 2008. Rhodes: IEEE. doi:10.1109/PESC.2008.4592385

Akagi, H. (1996). New trends in active filters for power conditioning. IEEE Transactions on Industry Applications, 32(6), 1312-1322. doi:10.1109/28.556633

Akagi, H. (2000). Active and hybrid filters for power conditioning. In Proceedings of the 2000 IEEE international symposium on industrial electronics, ISIE 2000 (pp.TU26-TU36). Puebla: IEEE. doi:10.1109/ISIE.2000.930470

Akagi, H., Kanazawa, Y., \& Nabae, A. (1984). Instantaneous reactive power compensators comprising switching devices without energy storage components. IEEE Transactions on Industry Applications, 20(3), 625-630. doi:10.1109/ TIA.1984.4504460

Benchaita, L., Saadate, S., \& Salem, A. (1999). A comparison of voltage source and current source shunt active filter by simulation and experimentation. IEEE Transactions on Power Systems, 14(2), 642-647. doi:10.1109/59.761892

Biricik, S. (2013). A novel hybrid active power filter topology for harmonic current suppression and reactive power compensation (PhD Thesis). Nicosia: Near East University.

Biricik, S., \& Ozerdem, O. C. (2010). Investigation of switched capacitors effect on harmonic distortion levels and performance analysis with active power filter. Journal of Electrical Review, Przeglad Elektrotechniczny, 11a(86), 13-17.

Biricik, S., \& Ozerdem, O. C. (2011). Harmonic distortion comparison of switched capacitors with active power filter for reactive power compensation. In EEEIC 9th international conference on environment and electrical engineering (pp. 269-272). Prague, Check Republic: IEEE. doi:10.1109/EEEIC.2010.5489949

Biricik, S., Ozerdem, O. C., Redif, S., \& Kmail, M. O. I. (2012). Novel hybrid active power filter structure to compensate harmonic currents and reactive power. In 16th IEEE Mediterranean Electrotechnical Conference, (pp. 597-601). Tunisia: IEEE. doi:10.1109/MELCON.2012.6196503.

Biricik, S., Ozerdem, O. C., Redif, S., \& Kmail., M. O. I. (2013). Performance improvement of active power filter under distorted and unbalanced grid voltage conditions. Journal of Electronics and Electrical Engineering (Elektronika Ir Elektrotechnika), 19(1), 35-39. http://dx.doi.org/10.5755/j01.eee.19.1.3247

Biricik, S., Redif, S., Ozerdem, O. C., Khadem, S. K., \& Basu, M. (2014). Real-time control of shunt active power filter under distorted grid voltage and unbalanced load condition using self tuning filter. IET Power Electronics, $7(7)$, 1895-1905. doi:10.1049/iet-pel.2013.0924

Buso, S., Malesani, L., \& Mattavelli, P. (1998). Comparison of current control techniques for active filter applications. IEEE Transactions on Industrial Electronics, 45(5), IEEE, 722-729. doi:10.1109/41.720328

Chatterjee, K., Fernandes, B. G., \& Dubey, G. K. (1999). An instantaneous reactive volt-ampere compensator and harmonic suppressor system. IEEE Transactions on Power Electronics, 14(2), 381-392. doi:10.1109/63.750192

Chen, Q., Chenl, Z., \& McCotmick, M. (2004). The application and optimization of C-type filter in a combined harmonic power filter. In 35th Annual IEEE power electronics specialists conference. (pp. 1041-1045). Aachen, Germany: IEEE. doi:10.1109/PESC.2004.1355564

Fujita, H., \& Akagi, H. (1991). Design strategy for the combined system of shunt passive and series active filters. In IEEE industry applications society annual meeting. (pp. 898-903). Dearborn, MI: IEEE, doi:10.1109/IAS.1991.178344

Ghamri, A., Benchouia, M. T., \& Golea, A. (2012). Sliding-mode control based three-phase shunt active power filter: Simulation and experimentation. Electric Power Components and Systems, 40(4), 383-398. doi:10.1080/ 15325008.2011.639127

Grady, W. M., \& Santoso, S. (2001). Understanding power system harmonics. IEEE Power Engineering Review, 21(11), IEEE, 8-11. doi:10.1109/MPER.2001.961997 
Kale, M., \& Özdemir, E. (2005). Harmonic and reactive power compensation with shunt active power filter under nonideal mains voltage. Electric Power Systems Research, 74(3), 363-370. doi:10.1016/j.epsr.2004.10.014

Khadem, S. K., Basu, M., \& Conlon, M. F. (2013). Harmonic power compensation capacity of shunt active power filter and its relationship with design parameters. IET Power Electronics, 7(2), 418-430. doi:10.1049/iet-pel.2013.0098

Moran, L. A., Dixon, J. W., \& Wallace, R. R. (1995). A three-phase active power filter operating with fixed switching frequency for reactive power and current harmonic compensation. IEEE Transactions on Industrial Electronics, 42(4), 402-408. doi:10.1109/41.402480

Nassif, A. B., Wilsun, X., \& Walmir, F. (2009). An investigation on the selection of filter topologies for passive filter applications. IEEE Transactions on Power Delivery, 24(3), 1710-1718. doi:10.1109/TPWRD.2009.2016824

Ozerdem, O. C., \& Biricik, S. (2009). A research and solution proposal for reactive power problems in North Cyprus Industries. In 6th International conference on electrical and electronics engineering (ELECO 2009). (pp. I-85-I-87). Bursa, Turkey: IEEE.

Rahmani, S., Hamadi, A. B., \& Al-Haddad, K. (2012). A comprehensive analysis of hybrid active power filter for power quality enhancement. In 38th Annual Conference on IEEE Industrial Electronics Society (IECON 2012). (pp. 6258-6267). Montreal: IEEE.

Singh, B. N. (2002). Implementation of a hybrid filter with a potential application to adjustable speed compressor drives for air quality control. Electric Power Components and Systems, 30(11), 1091-1126. doi:10.1080/ 15325000290085406

Singh, B., Al-Haddad, K., \& Chandra, A. (1999). A review of active filters for power quality improvement. IEEE Transactions on Industrial Electronics, 46(5), 960-971, IEEE. doi:10.1109/41.793345

Singh, G. K., Singh, A. K., \& Mitra, R. (2007). A simple fuzzy logic based robust active power filter for harmonics minimization under random load variation. Electric Power Systems Research, 77(8), 1101-1111. doi:10.1016/j. epsr.2006.09.006

Ucar, M., \& Ozdemir, E. (2008). Control of a 3-phase 4-leg active power filter under non-ideal mains voltage condition. Electric Power Systems Research, 78(1), 58-73. doi:10.1016/j.epsr.2006.12.008

Venkatesh, C., Sarma, D. V. S. S., \& Sydulu, M. (2009). S-transform-based hybrid active filter for mitigation of current harmonics. Electric Power Components and Systems, 37(12), 1305-1320. doi:10.1080/15325000903054977

Wildi, T. (2006). Electrical machines, drives, and power systems. Upper Saddle River, NJ: Prentice Hall.

Yacamini, R. (1995). Power system harmonics. Part 3: Problems caused by distorted supplies. IET Power Engineering Journal, 9(5), 233-238. doi:10.1049/pe:19950507 